\title{
PREVALENCE OF HEPATITIS C VIRUS IN PATIENTS WITH RELAPSING REMITTING MULTIPLE SCLEROSIS
}

\author{
Mahmoud Hemeda Al Rakawy ${ }^{1}$, Azza Abdel Nasser Abdel Aziz ${ }^{1}$, Dina Mohamed \\ Abd El-Gawaad ${ }^{1}$, Doaa Abd Allah Alidy ${ }^{1}$, Doaa Mohamed Abd ElAziz ${ }^{2}$, and \\ Shaimaa S. Khater ${ }^{1}$
}

\section{Department of Neurology and clinical pathology, Ain- Shams University Faculty of Medicine, Cairo, Egypt \\ Corresponding author: \\ Shaimaa Sayed Khater \\ Mobile: 01112424190 \\ E mail: \\ drshaimaasayedkhater@gmail. com}

Received: 28/4/2019

Accepted: $26 / 5 / 2019$

\begin{abstract}
Background: Multiple sclerosis (MS) is a chronic autoimmune illness of the central nervous system and is considered the most common non-traumatic cause of neurological disability in middle age, Hepatitis $C$ virus (HCV) is endemic in our country and Egypt is the most affected nation by HCV worldwide, this study is an educational hospital based study.
\end{abstract}

Aim of the Work: To determine prevalence of HCV in patients having relapsing remitting multiple sclerosis (RRMS).

Patients and Methods: Two hundred and three Egyptian patients with the diagnosis of RRMS were recruited consecutively from MS Unit of Neurology department at Ain Shams University Hospital which is the biggest MS unit in Egypt, Cross sectional pilot study. Patients' medical history, general and neurological examination including assessment of the functional disability using Expended Disability Status Scale (EDSS) were obtained along 6 months and were followed for 1 year and all subjects underwent serum sampling for detection of the HCV antibody by enzyme linked immunosorbent assay(ELISA) technique and confirmed diagnosis by polymerase chain reaction $(P C R)$.

Results: Data showed that prevalence of HCV among studied patients with RRMS was 4.9\% (no. 10 from 203), however prevalence of HCV in Egypt is 10.6\%, it may be due to gender predilection which is nearly 2:1 male to female in HCV versus 1:2.57 in MS patients,

Conclusion: $\mathrm{HCV}$ is less prevalent in MS patients than general population and patients with HCV have more active disease regarding relapses and magnetic resonant imaging (MRI) activity.

Keywords: Multiple sclerosis, Hepatitis C virus, Egyptian patients.

\section{INTRODUCTION:}

Multiple sclerosis (MS) is a complex immune mediated disorder of central nervous system. Multiple sclerosis is the most common non-traumatic cause of neurological disability in middle adulthood ${ }^{(1)}$.

There are four clinical phenotypes of MS. Initially, more than $80 \%$ of individuals with MS experience a relapsing-remitting disease course (RRMS) characterized by clinical exacerbations of neurologic symptoms followed by complete or incomplete remission. After 10 to 20 years, or median age of 39.1 years, about half of them gradually accumulate irreversible neurologic deficits with or without clinical relapses, which is known as secondary 
progressive MS (SPMS). Another 10\% to $20 \%$ of individuals with MS are diagnosed with primary progressive MS (PPMS), clinically defined as a disease course without any clinical attacks or remission from onset $^{(2)}$.

In general, the researchers found that MS prevalence has increased dramatically in that 5 year span, up $10 \%$ and now affecting 2.3 million people worldwide. Whether this is due to a true intrinsic increase in prevalence or whether the condition is being better diagnosed and reported is not clear. For instance, the number of neurologists worldwide has increased by $30 \%$, which might mean that MS is being better diagnosed and reported. Either way, we now know the prevalence is much higher than we previously thought ${ }^{(3)}$.

Traditionally, microbiologists have used Koch's postulates to establish whether a particular microbe causes a specific disease. Koch's postulates, however, are applicable only for highly pathogenic bacteria, which cause disease in most people they infect, and for organisms that can be cultured in the laboratory and can infect other hosts in addition to human beings ${ }^{(4)}$.

Koch's postulates are ill suited for most viral infections, especially slow viral infections, and for diseases caused by viruses that are a rare manifestation of a common infection ${ }^{(5)}$.

Hepatitis $\mathrm{C}$ virus (HCV) has a major impact on public health with over 170 million infected individuals. It has been considered to cause $25 \%$ of hepatocellular carcinoma (HCC) and $27 \%$ of cirrhosis cases all over the world. Death rate due to HCV infection is very high and approximately 350, 000 people die every year after being infected with HCV. Toxicity, resistance and cost of the treatment limit current therapy of $\mathrm{HCV}$. To date, no vaccine or immunetherapy is available ${ }^{(6)}$.
Egypt has one of the highest prevalence rates of hepatitis $\mathrm{C}$ virus infection in the world. The HCV epidemic appears to have been initiated by vigorous public-health campaigns using intravenous tartar emetic from the $1950 \mathrm{~s}$ until 1982 to eradicate schistosomiasis. This iatrogenic mode of infection has now resulted in a high incidence of hepatic morbidity and mortality from the late complications of $\mathrm{HCV}$ infection, such as chronic hepatitis, cirrhosis and hepatocellular carcinoma (HCC). Among the six major HCV genotypes found worldwide, genotype 4 is the most predominant in Egypt with $4 \mathrm{a}$ as the dominant subtype ${ }^{(7)}$.

\section{AIM OF THE WORK:}

To determine prevalence of $\mathrm{HCV}$ in patients having RRMS

\section{PATIENTS AND METHODS:}

Cross sectional pilot study conducted on 203 Patients with clinically definite relapsing remitting MS according to McDonald's criteria 2010, recruited from the MS unit and I med system, Ain Shams University.

\section{Inclusion criteria:}

All patients who were already diagnosed as RRMS attending the unit were recruited from May 2016 to May 2017.

\section{Exclusion criteria:}

Patients with other clinical multiple sclerosis types, patients with other medical or neurological diseases such as hypertension and diabetes mellitus, cardiac diseases, patient with a contraindication to perform MRI, patients who were previously diagnosed chronic liver diseases.

\section{Patients characteristics:}

Patients Aged 16 till 50 years both sexes were included, diagnosis of RRMS patients 
with the McDonald diagnostic criteria for multiple sclerosis.

\section{Procedure:}

\section{Patients were subjected to the following:}

History taking and complete neurological examination as chronic liver diseases may previously affecting the clinical picture of the patients, level of disability from MS assessed with the Extended Disability Status Score (EDSS). Duration of illness was calculated as time since first symptoms in years, brain MRI with contrast \pm MRI cervicodorsal spines, $\mathrm{HCV} \mathrm{Ab}$ screening by commercially available ELISA kits in El Demerdash internal medicine laboratory, patients with positive results will be subjected to

1. PCR quantitative tests examination.

2. All of the patients will be subjected to the following at 0,6 months and during relapse.

a. Full clinical evaluation including medical, neurological history and examination.

b. EDSS scoring.

c. MRI brain and/or spinal cord with contrast.

\section{Statistical analysis of data:}

The collected data was revised, coded, tabulated and introduced to a PC using Statistical package for Social Science (IBM Corp. Released 2011. IBM SPSS Statistics for Windows, Version 20.0. Armonk, NY: IBM Corp). Data was presented and suitable analysis was done according to the type of data obtained for each parameter.

\section{A. Descriptive statistics:}

1. Mean, Standard deviation $( \pm$ SD) and range for parametric numerical data, while Median and Interquartile range (IQR) for non parametric numerical data.

2. Frequency and percentage of nonnumerical data.

\section{B. Analytical statistics:}

1. Student $\mathbf{T}$ Test was used to assess the statistical significance of the difference between two study group means.

2. Mann Whitney Test (U test) was used to assess the statistical significance of the difference of a non-parametric variable between two study groups.

3. ANOVA test was used to assess the statistical significance of the difference between more than two study group means.

4. Correlation analysis (using Pearson's method): To assess the strength of association between two quantitative variables. The correlation coefficient denoted symbolically " $r$ " defines the strength and direction of the linear relationship between two variables.

5. Chi-Square test was used to examine the relationship between two qualitative variables.

6. Fisher's exact test: was used to examine the relationship between two qualitative variables when the expected count is less than 5 in more than $20 \%$ of cells.

- P-value: level of significance

- $\mathrm{P}>0.05$ : Non significant (NS).

- $\mathrm{P}<0.05$ : Significant (S).

- $\mathrm{P}<0.01$ : Highly significant (HS).

\section{RESULTS:}

This is a cross sectional pilot study was conducted during the period from August 2016 to August 2017. The case group included 203 patients with age range from 16-52 years with the diagnosis of RRMS whom were recruited consecutively after their recent conscent to participate in the study and all of them have their records in the MS database Imed system. 
As Regards the demographic data, the sample included 53(26\%) males and 150
$(73 \%)$ females, $18(8.9 \%)$ smoker, 10 $(4.9 \%)$ have family history (Table 1$)$.

Table (1): Demographic data of studied patients with MS N=203:

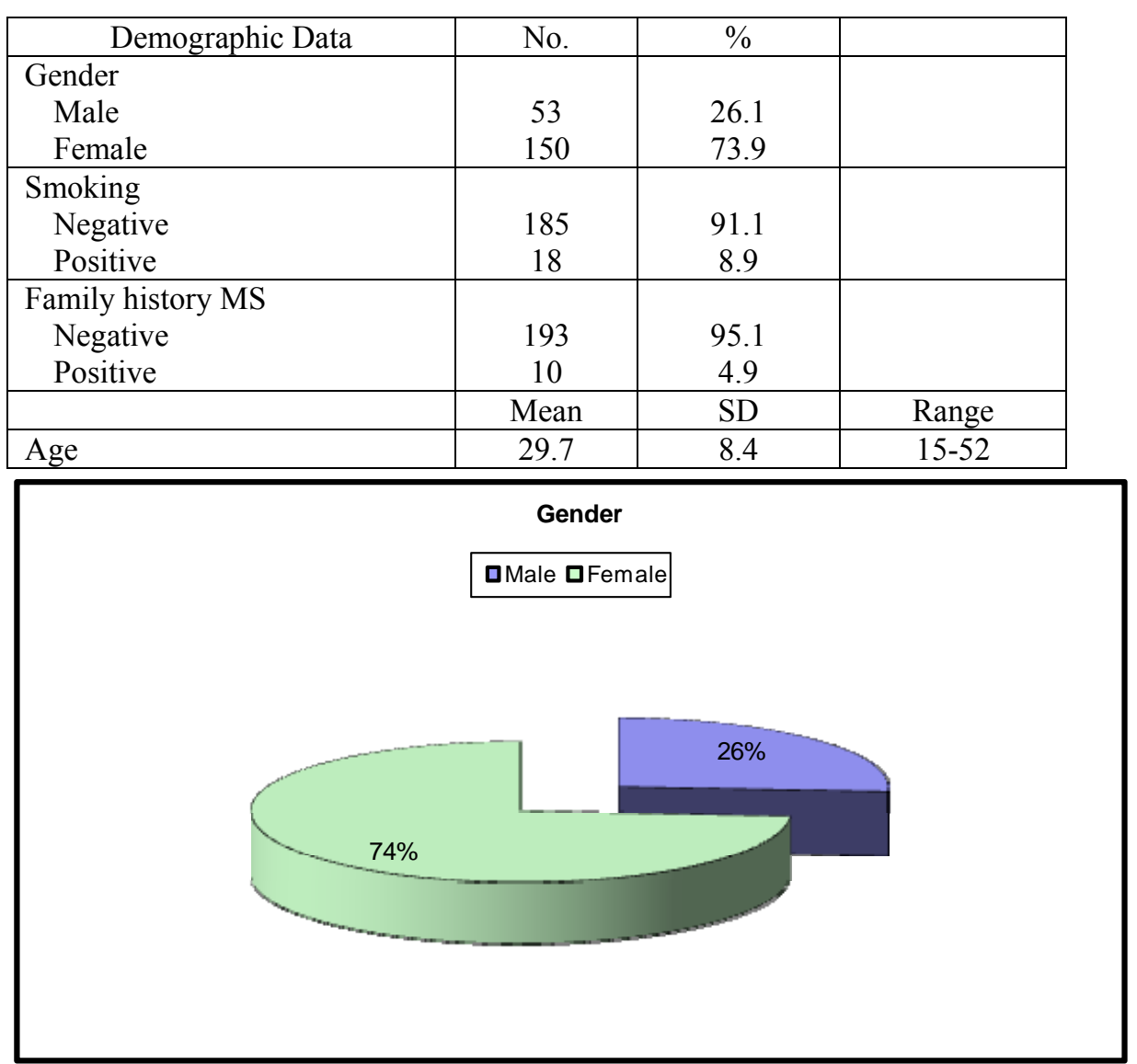

Diagram (1): Distribution of gender of studied patients.

Table (2): Distribution of symptoms of MS at onset $\mathrm{N}=203$

\begin{tabular}{|c|c|c|}
\hline Symptoms at onset & No. & \% \\
\hline Visual symptoms & 38 & $18.7 \%$ \\
\hline Sensory & 38 & $18.7 \%$ \\
\hline Motor & 45 & $22.2 \%$ \\
\hline Focal spinal & 20 & $9.9 \%$ \\
\hline Cerebellar & 10 & $4.9 \%$ \\
\hline Combined & 26 & $12.8 \%$ \\
\hline Brain stem & 26 & $12.8 \%$ \\
\hline
\end{tabular}




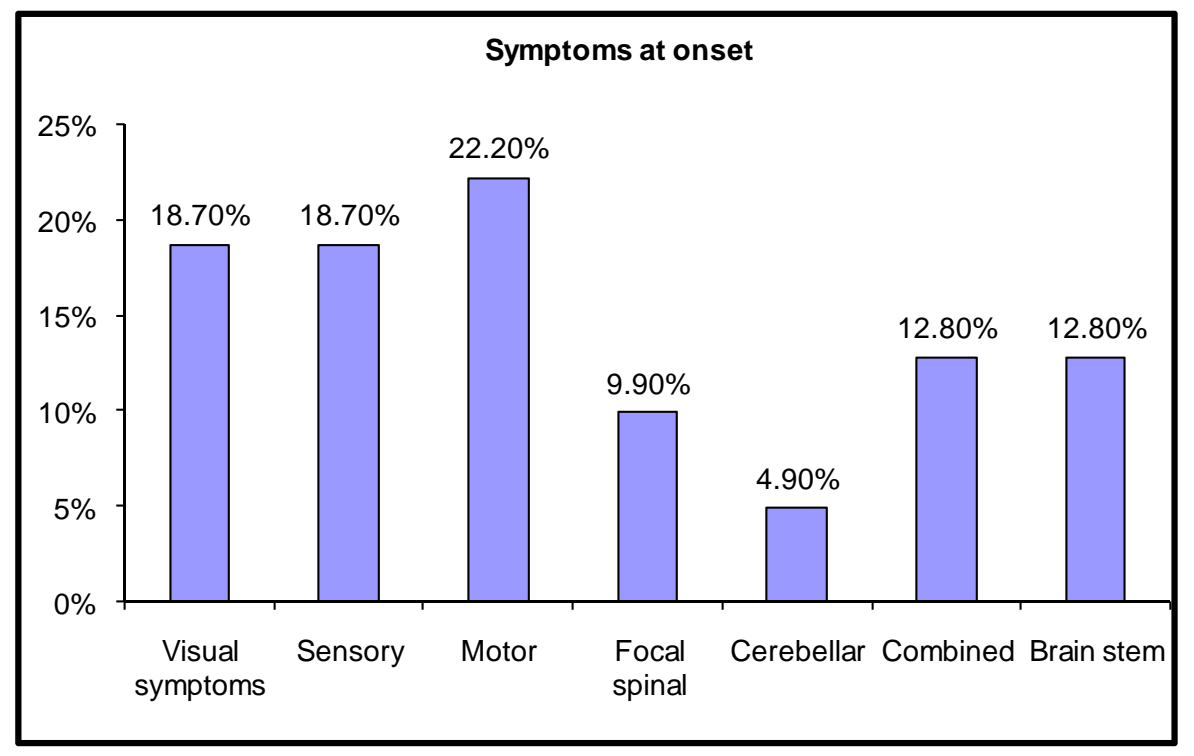

Diagram (2): Distribution of symptoms of MS on presentation.

As regards distribution of symptoms of MS on presentation, It was found that 45 $(22.2 \%)$ of patients were presenting with motor symptoms, followed by visual and sensory symptoms 38 (18.7\%), Then brain stem and compound symptoms were 26 $(12.8 \%)$, Then focal spinal $20(9.9 \%)$, and lastly cerebellar $10(4.9 \%)$.

\section{DISCUSSION:}

MS is a demyelinating Autoimmune disease with different clinical forms and uncertain etiology. Many studies suggest that it is likely caused by infections triggering a systemic immune response resulting in antigen/non-antigen-related autoimmune response in $\mathrm{CNS}^{(8)}$.

Hepatitis $\mathrm{C}$ virus (HCV) infection is a leading cause of cirrhosis, hepatocellular carcinoma, and liver transplantation. A better understanding of $\mathrm{HCV}$ disease progression and the associated cost can help the medical community manage $\mathrm{HCV}$ and develop treatment strategies in light of the emergence of several potent anti-HCV therapies $^{(9)}$.

$\mathrm{HCV}$ is endemic in our country and Egypt is the most affected nation by HCV worldwide, so the government initiated a campaign to screen $\mathrm{HCV}$ in whole country as a part of WHO project to eradicate HCV by 2030 , at the same time prevalence of MS is increasing, that inspire the idea of studying the prevalence of $\mathrm{HCV}$ in those who have MS, It is a novel idea hasn't been studied yet, so will discuss the results with the most mimic to MS which is CNS vasculitis and the most incriminated pathogen in infectious theory of MS which are EBV and CMV.

This study is a hospital based cross sectional pilot study which was carried in MS unit at faculty of medicine in Ain shams university - Cairo- Egypt, it was carried out on 203 RRMS patients group according to Revised McDonald criteria 2010 ${ }^{(10)}$, they were studied to detect $\mathrm{HCV} \mathrm{Ab}$ in serum using ELISA technique in the plasma samples of those patients, the study is aiming to know the possible association of $\mathrm{HCV}$ as a risk factor for MS disease.

These results showed that prevalence of HCV among studied patients with RRMS was $4.9 \%$ (no. 10 from 203), however prevalence of HCV in Egypt is $10.6 \%$ as postulated by Gomaa et al. ${ }^{(11)}$, it may be due to gender predilection which is nearly $2: 1$ in $\mathrm{HCV}$ versus 1:2 in MS patients. 
Regarding the age the results showed that the seropositive patients had higher age than the seronegative patients and the difference is borderline significant $(\mathrm{P}=0.08)$ which is consistent with previous study of $\mathrm{HCV}$ related cerebral vasculitis, the $\mathrm{HCV}$ vasculitis patients had higher age than $\mathrm{HCV}$ controls $^{(12)}$.

Results showed that there was no significant difference $\mathrm{HCV}$ positive and negative MS cases as regards gender, yet higher female gender in both groups $(\mathrm{P}=0.6)$, which is consistent with study of $\mathrm{HCV}$ related vasculitis, the $\mathrm{HCV}$ vasculitis patients have higher female gender but with not statistically significant Milvia et al. ${ }^{(12)}$. The results are consistent with Aziz et al. ${ }^{(13)}$ that postulated that There was no significant association between the EBV antibody titre and sex $(\mathrm{P}=0.857)$. On contrary Mouhieddine et al. ${ }^{(14)}$ reported that older and female gender were associated with a higher anti-VCA titer Anti-EBV-VCA (Viral Caspid Antigen) Ig G. Higher female gender may be due to more active immune system with higher IgG levels and a highly active immune system might be one mechanism behind the over representation of females seen in autoimmune diseases like MS.

The results showed that the $4.9 \%$ of patients have family history of MS and positive smoking in $8.9 \%$ of the studied patients, similarly an Ain Shams University MS unit study of EBV ab in patients of RRMS showed that a positive family history (FH) of MS (3.6\%) by Aziz et al. ${ }^{(13)}$.

\section{Conclusion:}

$\mathrm{HCV}$ is endemic in our country and Egypt is the most affected nation by $\mathrm{HCV}$ worldwide, and HCV hasn't been studied yet as a virus incriminated in MS as a risk factor or even its effect on clinical aspect in such patients compared to others free from HCV. Our study was the first to discuss about two of the most important diseases that may be burden on the patient and handicapping, so it may be a key to other upcoming studies in the future.

\section{REFERENCES}

1. Tullman MG (2013): Overview of the epidemiology, diagnosis and disease progression associated with multiple sclerosis. The American journal of managed care; 19 (2):15-20

2. He D, Xu Z, Dong S, Zhang H, Zhou H, et al. (2012): Teriflunomide for multiple sclerosis The Cochrane Collaboration. Published by John Wiley \& Sons; Ltd.

3. Multiple sclerosis international federation (2013): MS atlas. Available on website at: https://www.msif. org/aboutus/advocacy/atlas/ Accessed 2/2017.

4. Wu C, Yosef N, Thalhamer T, Zhu C, Xiao S, Kishi Y, et al. (2013): Induction of pathogenic TH17 cells by inducible saltsensing kinase SGK1. Nature; 496:513-7.

5. Kleinewietfeld $M$, Manzel A, Titze J, Kvakan H, Yosef N, Linker RA, et al. (2013): Sodium chloride drives autoimmune disease by the induction of pathogenic TH17 cells. Nature; 496:518-22.

6. Suliman Qadir Afridi, Muhammad Nouman Zahid, Muhammad Zubair Shabbir, et al. (2013): Prevalence of HCV genotypes in district Mardan. Virology Journal; 10:90.

7. Mohamed Abdel-Hamid, Mai El-Daly, Vilma Molnegren, et al. (2007). Genetic diversity in hepatitis $\mathrm{C}$ virus in Egypt and possible association with hepatocellular carcinoma. Journal of General Virology; 88: 1526-31.

8. Migliara G, Mueller M, Piermattei A, Brodie C, Paidas MJ, Barnea ER, Ria F (2017): PIF* promotes brain re-myelination locally while regulating systemic inflammationclinically relevant multiple sclerosis $\mathrm{M}$. smegmatis model. Oncotarget; 8(13):21834.

9. Razavi H, ElKhoury AC, Elbasha E, et al. (2013): Chronic Hepatitis C Virus (HCV) Disease Burden and Cost in the United States. Hepatology; 57: 2164-70. 
10. Polman $\mathrm{CH}$, Reingold SC, Banwell B, Clanet M, Cohen JA, FilippiM, Fujihara K, Havrdova E, Hutchinson M, Kappos L, LublinFD, Montalban X, O'Connor P, Sandberg-Wollheim M, Thompson AJ, Waubant E, Weinshenker B, Wolinsky JS (2011): Diagnostic criteriafor multiple sclerosis: 2010 revisions to the McDonald criteria.Ann Neurol; 69:292-302.

11. Gomaa A, Allam N, Elsharkway A, El Kassas M, Waked I. Hepatitis C infection in Egypt: prevalence, impact and management strategies. Hepatic medicine: evidence and research. 2017; 9:17.

12. Milvia M, Saadoun D, Marchetti A, Limal N, Picq C, Pantano P, Galanaud D, Cianci R, Duhaut P, Piette JC, Fiorilli M. Central nervous system involvement in hepatitis $\mathrm{C}$ virus cryoglobulinemia vasculitis: a multicenter case-control study using magnetic resonance imaging and neuropsychological tests. The Journal of Rheumatology. 2017; 32(3):484-8.

13. Aziz AA, Fouad MM, Mahmoud AH, Hafeez MA, Swelam MS, Abou Steit AM, Khater SS, Salah NM, Mahmoud AE, Ahmed HA (2018): Epstein-Barr virus antibodies in a sample of Egyptian patients with relapsing-remitting multiple sclerosis. Multiple Sclerosis Journal 2018; 24(2): NP28-NP28).

14. Mouhieddine TH, Darwish H, Fawaz L, Yamout B, Tamim H, Khoury SJ (2015): Risk factors for multiple sclerosis and associations with anti-EBV antibody titers. Clinical Immunology; 158(1):59-66. 
مدى أنتشار فيروس كبدي سي في مرضى التصلب المتعدد بالجهاز العصبي المركزي

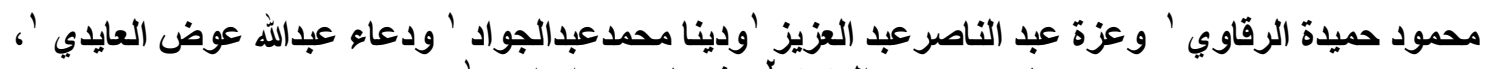

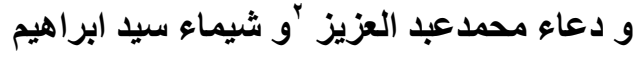

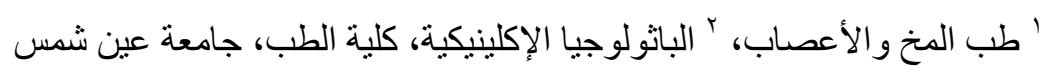

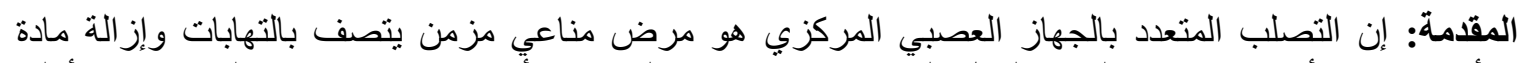

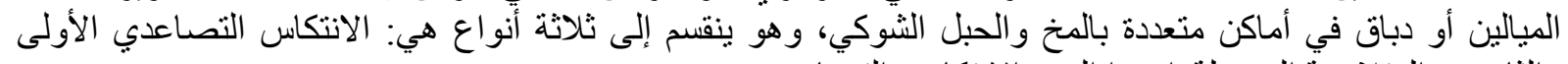

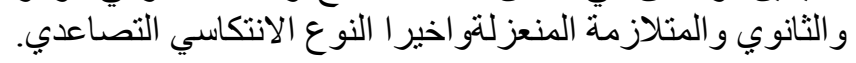

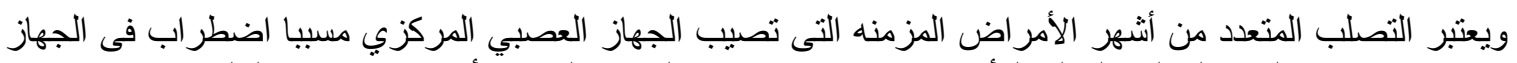

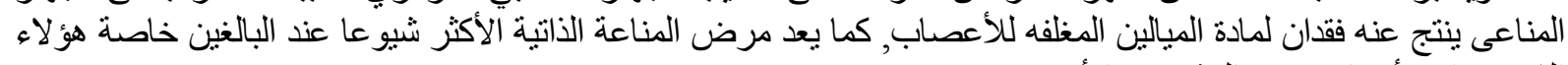
الذين نتر اوح أعمار هم بين العشرين وان الأربعين.

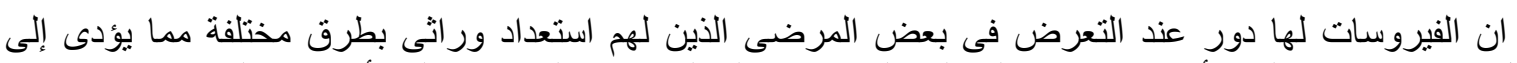

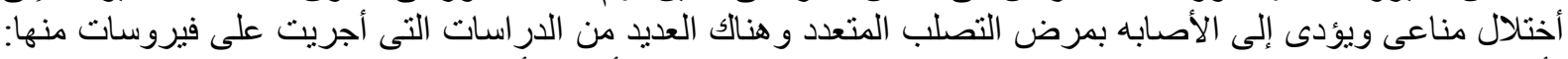

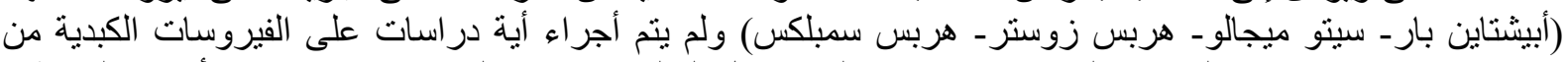

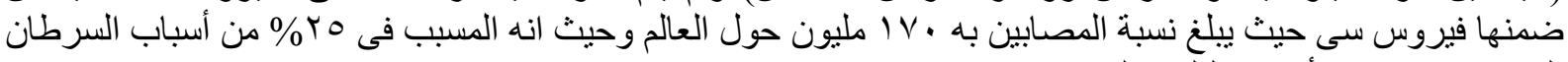

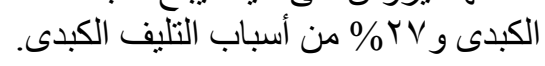

الهذف من البحث: فكرة هذه الدراسة هى نسبة انتشار فيروس سى لدى المرضى المصابين بالتصلب المتعدد

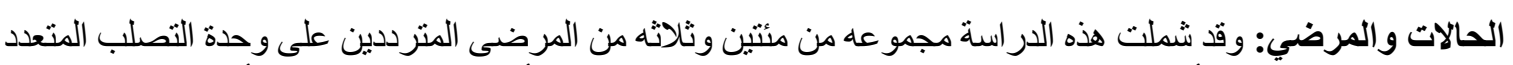

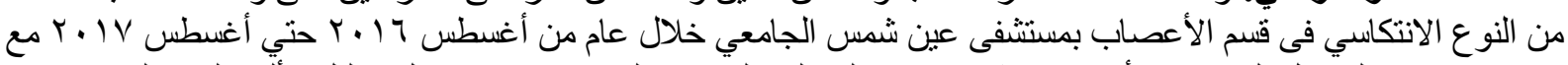

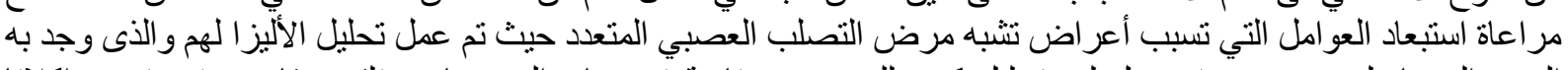

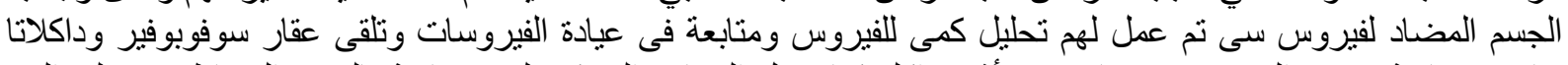

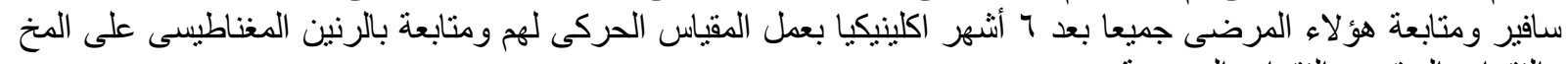
والفقرات العنقيه 土 الفقر ات الصدرية.

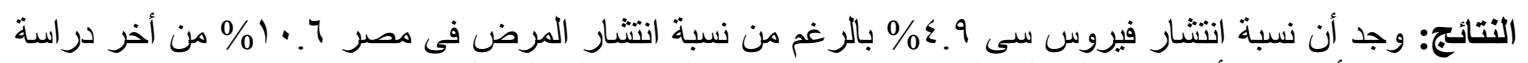

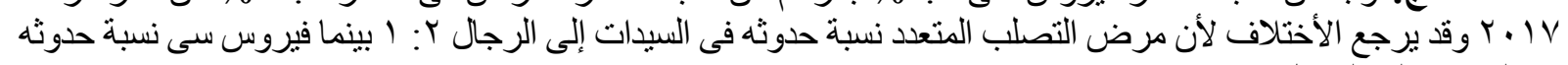

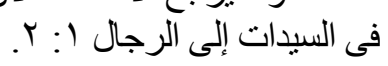

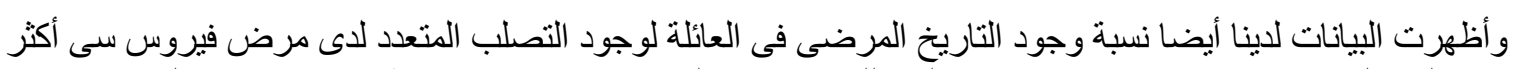

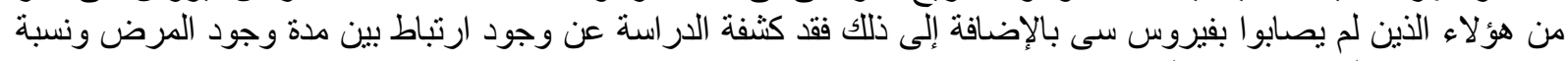

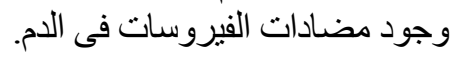

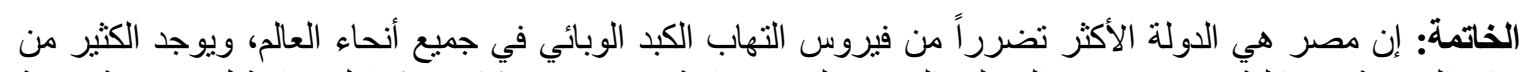

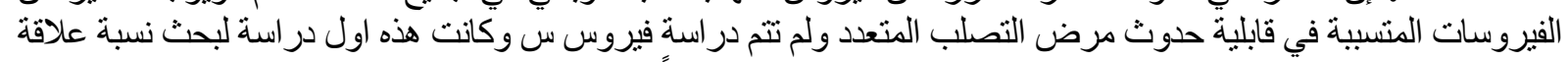

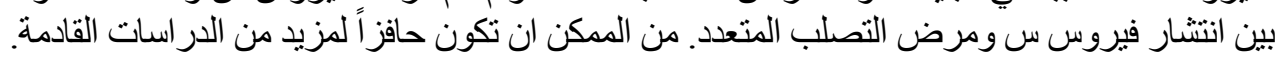

